\title{
Hypocapnia as a poor prognostic factor in aneurysmal subarachnoid hemorrhage
}

\author{
Paul Foreman ${ }^{1}$, Christoph J Griessenauer ${ }^{1}$, Mohammadali M Shoja ${ }^{1,2^{*}}$ and R Shane Tubbs ${ }^{2}$
}

\begin{abstract}
In this editorial, the issues of hypocapnia and its relation to symptomatic vasospasm, prognosis, and outcome among patients with aneurysmal subarachnoid hemorrhage is discussed. Potential directions for future studies are provided.
\end{abstract}

Keywords: Hypocapnia, $\mathrm{CO}_{2}$, Cerebral vasospasm, Subarachnoid hemorrhage, Outcome

Global incidence of aneurysmal subarachnoid hemorrhage (aSAH) is estimated at approximately 10 per 100,000, with some 20,000-30,000 new cases occurring each year in the United States. Despite comprising only $5 \%$ of strokes, aSAH accounts for a significant proportion of strokerelated morbidity and mortality. In-hospital mortality rate approaches nearly $30 \%$ and approximately $10-20 \%$ of survivors remain functionally dependent. Despite overall improvements in fatality and outcome in recent decades, aSAH still remains a significant source of stroke-related morbidity and mortality. This has led to an intensive research effort to improve the care and outcome of these critically ill patients [1].

The impact of hyperventilation with subsequent hypocapnia in the setting of traumatic brain injury (TBI) has been studied extensively. Carbon dioxide $\left(\mathrm{CO}_{2}\right)$ is a potent dilator of the cerebrovasculature and induced hyperventilation is an established mean to reduce the intracranial pressure (ICP) through cerebral vasoconstriction. While effective in reducing elevated ICP, the vasoconstrictive effect of hypocapnia can exacerbate cerebral ischemia [2] in the traumatized brain producing deleterious effects on the neurologic outcome [3]. In addition to the deleterious effects on the CNS, hypocapnia has also been shown to negatively impact organ-tissue perfusion of subcutaneous tissue and muscle [4], stomach [5,6], and bowel [7]. This has led to guideline recommendations against the use of prophylactic hyperventilation in the setting of TBI; rather,

\footnotetext{
* Correspondence: shoja.m@gmail.com

${ }^{1}$ Department of Neurosurgery, Univeristy of Alabama at Birmingham, Birmingham, AL, USA

${ }^{2}$ Pediatric Neurosurgery, Children's Hospital, Birmingham, AL, USA
}

hyperventilation is only to be used as a temporizing measure for the reduction of elevated ICP [8]. Similar deleterious findings have been demonstrated in the setting of acute cerebrovascular accidents (CVA) [9]. An early study evaluating the association between respiratory patterns and arterial blood gas tensions in the setting of CVA found hyperventilation, hypocapnia, and arterial alkalosis to be associated with poor prognosis [9]. While much of the current literature focuses on the effects of permissive hyperventilation, a recent prospective study of spontaneous hyperventilation produced similar results [10].

Cerebral blood flow is compromised following aSAH [11]. While permissive hyperventilation is rarely utilized for the treatment of elevated ICP in aSAH patients, the development of spontaneous, central hyperventilation with resultant hypocapnia has been observed in aSAH patients. Concerns about the effect of this spontaneous reduction of $\mathrm{CO}_{2}$ on the cerebral blood flow in these patients has led to investigation into the incidence of hypocapnia and its relationship with outcome in aSAH patients [12]. Solaiman et al. have retrospectively assessed a cohort of 102 mechanically ventilated patients suffering an aSAH in an effort to demonstrate the incidence of hyperventilation and hypocapnia, as well as to determine its association with symptomatic vasospasm and clinical outcome [12]. Hypocapnia, as defined by a $\mathrm{PaCO}_{2}$ of less than $35 \mathrm{mmHg}$, was reported at least once during the intensive care unit stay in $99 \%$ of patients. Ninety-four patients (92\%) had at least 1 day in which all $\mathrm{PaCO} 2$ measurements were below $35 \mathrm{~mm} \mathrm{Hg}$. Sixty-three percent of patients had episodes with $\mathrm{PaCO}_{2}$ of less than $30 \mathrm{~mm} \mathrm{Hg}$. Median duration of hypocapnia (defined by the number of days in which any $\mathrm{PaCO} 2$ 
measurement in a given day was $<35 \mathrm{~mm} \mathrm{Hg}$ ) was 4 days. Interestingly, the majority of patients were spontaneously breathing with minimal ventilator support suggesting a central mechanism for hyperventilation. Intentional hyperventilation for impending herniation was not performed. The duration of hypocapnia was found to be independently associated with symptomatic vasospasm [adjusted odds ratio $(\mathrm{OR})=1.25(95 \% \mathrm{CI}, 1.07-1.47)]$, and unfavorable outcome [adjusted OR $=1.33$ (95\% confidence interval $(\mathrm{CI})$, 1.04-1.70)]. Despite the statistically significant association, it should be noted that this remains an association rather than proof of causation. Regardless, given what is known about hypocapnia and cerebral blood flow, it makes sense that a reduction of $\mathrm{CO}_{2}$ could lead to reduced cerebral blood flow $[10,13,14]$, exacerbation of cerebral ischemia [2], and an increase in extracellular mediators of secondary brain injury [13]. It is very likely that the added physiologic stress from hypocapnia-induced brain ischemia, serves to exacerbate the already reduced cerebral blood flow present following aSAH, placing the patient at increased risk for cerebral infarction.

The identification of hypocapnia as a poor prognostic factor among aSAH patients raises the question as to whether tight $\mathrm{PaCO}_{2}$ control would improve outcome following aSAH or not [13]. This required ventilatory control through sedation and neuromuscular blockade, which by itself diminishes the quality of a clinical neurologic assessment and places the patients at risk for unidentified neurologic decline. While other modes of assessment (i.e. ICP monitoring, transcranial Doppler) can be simultaneously performed, they lack the sensitivity of a skilled neurologic exam. Therefore, aggressive control of a patient's ventiliatory status in exchange for the clinical neurologic exam may not be advisable. However, it can be assumed that avoidance of induced hyperventilation (in the absence of impending herniation) and the use of moderate sedation to target normocapnia is a reasonable approach. Based on the available data, it seems that further studies would be useful to fully elucidate the role of $\mathrm{CO}_{2}$ levels and its potential therapeutic and prognostic implications in the setting of aSAH. Whether or not a tight PaCO2 control would improve the outcome in this setting requires careful consideration and should be addressed in clinical trials.

\section{Competing interests}

The authors declare that they have no competing interest.

Received: 24 September 2013 Accepted: 21 November 2013

Published: 25 November 2013

\section{References}

1. Harrigan MR, Deveikis JP: Handbook of Cerebrovascular Disease and Neurointerventional Technique. 2nd edition. New York: Humana Press; 2013.

2. Coles JP, Fryer TD, Coleman MR, Smielewski P, Gupta AK, Minhas PS, Aigbirhio F, Chatfield DA, Williams GB, Boniface $S$, et al: Hyperventilation following head injury: effect on ischemic burden and cerebral oxidative metabolism. Crit Care Med 2007, 35:568-578.
3. Muizelaar JP, Marmarou A, Ward JD, Kontos HA, Choi SC, Becker DP, Gruemer H, Young HF: Adverse effects of prolonged hyperventilation in patients with severe head injury: a randomized clinical trial. J Neurosurg 1991, 75:731-739.

4. Akca O, Doufas AG, Morioka N, Iscoe S, Fisher J, Sessler DI: Hypercapnia improves tissue oxygenation. Anesthesiology 2002, 97:801-806.

5. Schwartges I, Picker O, Beck C, Scheeren TW, Schwarte LA: Hypercapnic acidosis preserves gastric mucosal microvascular oxygen saturation in a canine model of hemorrhage. Shock 2010, 34:636-642.

6. Schwartges I, Schwarte LA, Fournell A, Scheeren TW, Picker O: Hypercapnia induces a concentration-dependent increase in gastric mucosal oxygenation in dogs. Intensive Care Med 2008, 34:1898-1906.

7. Fleischmann E, Herbst F, Kugener A, Kabon B, Niedermayr M, Sessler DI, Kurz A: Mild hypercapnia increases subcutaneous and colonic oxygen tension in patients given $80 \%$ inspired oxygen during abdominal surgery. Anesthesiology 2006, 104:944-949

8. Bratton SL, Chestnut RM, Ghajar J, McConnell Hammond FF, Harris OA, Hart R, Manley GT, Nemecek A, Newell DW, Rosenthal G, et al: Guidelines for the management of severe traumatic brain injury XIV Hyperventilation. J Neurotrauma 2007, 24 Suppl 1:S87-S89.

9. Rout MW, Lane DJ, Wollner L: Prognosis in acute cerebrovascular accidents in relation to respiratory pattern and blood gas tensions. Br Med J 1971, 3:7-9.

10. Carrera E, Schmidt JM, Fernandez L, Kurtz P, Merkow M, Stuart M, Lee K, Claassen J: Sander Connolly E, Mayer SA, Badjatia N: spontaneous hyperventilation and brain tissue hypoxia in patients with severe brain injury. J Neurol Neurosurg Psychiatry 2010, 81:793-797.

11. Matsuda M, Shiino A, Handa J: Sequential changes of cerebral blood flow after aneurysmal subarachnoid haemorrhage. Acta Neurochir (Wien) 1990, 105:98-106.

12. Solaiman $\mathrm{O}$, Singh JM: Hypocapnia in aneurysmal subarachnoid hemorrhage: incidence and association with poor clinical outcomes. J Neurosurg Anesthesiol 2013, 25:254-261.

13. Marion DW, Puccio A, Wisniewski SR, Kochanek P, Dixon CE, Bullian L, Carlier $P$ : Effect of hyperventilation on extracellular concentrations of glutamate, lactate, pyruvate, and local cerebral blood flow in patients with severe traumatic brain injury. Crit Care Med 2002, 30:2619-2625.

14. Diringer MN, Videen TO, Yundt K, Zazulia AR, Aiyagari V, Dacey RG Jr, Grubb RL, Powers WJ: Regional cerebrovascular and metabolic effects of hyperventilation after severe traumatic brain injury. J Neurosurg 2002, 96:103-108

doi:10.1186/2045-9912-3-25

Cite this article as: Foreman et al:: Hypocapnia as a poor prognostic factor in aneurysmal subarachnoid hemorrhage. Medical Gas Research 2013 3:25.

\section{Submit your next manuscript to BioMed Central and take full advantage of:}

- Convenient online submission

- Thorough peer review

- No space constraints or color figure charges

- Immediate publication on acceptance

- Inclusion in PubMed, CAS, Scopus and Google Scholar

- Research which is freely available for redistribution 